\title{
Basement Membrane Thickness
}

National Cancer Institute

\section{Source}

National Cancer Institute. Basement Membrane Thickness. NCI Thesaurus. Code

C129676.

The dimension between the two surfaces of a basement membrane. 